\title{
Effects of Lyophilization of Arginine-rich Cell-penetrating Peptide-modified Extracellular Vesicles on Intracellular Delivery
}

\author{
KOSUKE NOGUCHI ${ }^{1}$, MAMI HIRANO ${ }^{1}$, TAKUYA HASHIMOTO ${ }^{2}$, EIJI YUBA ${ }^{2}$, \\ TOMOKA TAKATANI-NAKASE ${ }^{3}$ and IKUHIKO NAKASE ${ }^{1}$
}

\author{
${ }^{1}$ Department of Biological Science, Graduate School of Science, Osaka Prefecture University, Osaka, Japan; \\ ${ }^{2}$ Department of Applied Chemistry, Graduate School of Engineering, Osaka Prefecture University, Osaka, Japan; \\ ${ }^{3}$ School of Pharmacy and Pharmaceutical Sciences, Mukogawa Women's University, Hyogo, Japan
}

\begin{abstract}
Background/Aim: Extracellular vesicles (exosomes, EVs) (30-200 nm in diameter) are secreted by various cells in the body. Owing to the pharmaceutical advantages of EVs, an EV-based drug delivery system (DDS) for cancer therapy is expected to be the next-generation therapeutic system. However, preservation methods for functional and therapeutic EVs should be developed. Here, we developed the method of lyophilization of arginine-rich cell penetrating peptide (CPP)modified EVs and investigated the effects of lyophilization on the characteristics of EVs. Materials and Methods: Particle size, structure, zeta-potential, and cellular uptake efficacy of the arginine-rich CPP-modified EVs were analyzed. The model protein saporin (SAP), having anti-cancer effects, was encapsulated inside the EVs to assess the cytosolic release of EV content after cellular uptake. Results: Lyophilization of the EVs did not affect their particle size, structure, zeta-potential, and cellular uptake efficacy; however, the biological activity of the encapsulated SAP was inhibited by lyophilization. Conclusion: Lyophilization of EVs may affect SAP structures and/or reduce the cytosolic release efficacy of EV's content after cellular uptake and needs attention in EV-based DDSs.
\end{abstract}

Extracellular vesicles (exosomes, EVs) are cellular membrane vesicles (ca. 30-200 nm diameter) that are secreted from almost all the cells of the body (1-3). EVs are generated in multivesicular endosomes (MVEs) by inward budding of

Correspondence to: Ikuhiko Nakase, Department of Biological Science, Graduate School of Science, Osaka Prefecture University, 1-1, Gakuen-cho, Naka-ku, Osaka 599-8531, Japan. Tel: +81 722549895, Fax: +81 722549895, e-mail: i-nakase@21c.osakafuu.ac.jp

Key Words: Extracellular vesicles, exosomes, lyophilization, cellpenetrating peptides, saporin. cellular membranes. After fusion of plasma and MVE membranes, EVs are secreted and taken up by other cells via membrane fusion and endocytosis (1-3). Because of encapsulation of biofunctional molecules including microRNAs and enzymes in the MVEs, EVs participate in cell-to-cell communication and regulate cellular/body homeostasis and the progression of diseases such as cancer (14). In cancer cells, cell-to-cell communication based on EVs induces angiogenesis, tumor cell migration, metastasis, and immune response modulation $(2,3)$. EV-based diagnostics have gained increased attention owing to ability EVs to encapsulate disease-related proteins and microRNAs $(3,4)$. In addition, the development of EV-based drug delivery systems (DDSs) is highly expected to become the next-generation therapeutic system because of the several advantages of EVs, such as immunological control, usage of EV-based cell-to-cell communication routes, low toxicity, controlled and designed expression of protein in/on EVs, infinite secretion, and artificial/natural encapsulation of therapeutic molecular cocktails $(3,4)$. A receptor target system has been developed by expressing on EV membranes, through genetic engineering, a sequence that interacts with a receptor target. Examples include the central nervous system-specific rabies viral glycoprotein (RVG) peptide for targeting acetylcholine receptor (5), anti-epidermal growth factor receptor (EGFR) nanobodies fused with glycosylphosphatidylinositol (GPI) anchor signal peptides derived from decay-accelerating factor (DAF) (6), and designed ankyrin repeat proteins for targeting human epidermal growth factor receptor 2 (HER-2) (7). In recent years, our research group has successfully developed biofunctional peptide-modified EVs for EV-based DDS including the effective usage of artificial coiled-coil peptides for receptor targeting (epidermal growth factor receptor) (8), arginine-rich cell-penetrating peptides (CPPs) for enhanced cellular uptake via the macropinocytosis route $(9,10)$, and $\mathrm{pH}-$ sensitive fusogenic peptide for increased cytosolic release of 
EV content in the cells (11). Using these systems of peptide modification, the anti-cancer protein saporin (SAP) was successfully delivered into the targeted cancer cells in in vitro assays (8-11).

Usually, the EVs are frozen for long-term storage, and hence, preservation methods for functional and therapeutic EVs should be developed. Repeated freeze-thawing cycles easily induce destruction and/or fusion of the EVs (12). In recent years, different methods of lyophilization of EVs have been reported (12-14). Charoenviriyakul et al. have developed lyophilization methods using trehalose for EVs, resulting in the prevention of EV aggregation, as well as in the retention of their biological activity as analyzed using an in vivo assay (13). In this study, we applied a lyophilization method to argininerich CPP-modified EVs and studied the effects of lyophilization on EV characteristics including vesicular structure, cellular uptake efficacy, and cytosolic delivery of the EV content. We demonstrated that after lyophilization of the EVs and addition of $\mathrm{H}_{2} \mathrm{O}$ for their recovery, the particle size, structure, zeta-potential, and cellular uptake efficacy of the EVs were not affected; however, the biological activity of the encapsulated SAP, which has anti-cancer effects, was inhibited by lyophilization, warranting attention to EV-based DDSs.

\section{Materials and Methods}

Peptide synthesis. The acetylated-cysteinyl-glycine coupled with hexadeca-arginine residues (Ac-CG-R16) was synthesized by 9fluorenylmethyloxycarbonyl (Fmoc) solid-phase synthesis method on a Rink Amide resin with coupling reagents 1-hydroxybenzotriazole (HOBt)/2-(1H-Benzotriazole-1-yl)-1,1,3,3-tetramethyluronium hexafluorophosphate (HBTU) (Peptide Institute, Osaka, Japan)/Nmethylmorpholine (NMM) as previously described $(15,16)$. The Rink Amide resin and the Fmoc-amino acid derivatives were purchased from Shimadzu Biotech (Kyoto, Japan) and the Peptide Institute (Osaka, Japan). The $N$-terminals of the peptide resin were acetylated with acetic anhydride in the presence of NMM in dimethylformamide (DMF) (17). Deprotection of the protecting group included in the peptide sequence and cleavage from resin were performed by treatment with trifluoroacetic acid (TFA)/ethanedithiol (EDT) mixture (95:5) for $3 \mathrm{~h}$ at $25^{\circ} \mathrm{C}$. The deprotected peptides were purified by high-performance liquid chromatographic (HPLC) purification, and the molecular weight of the detected peptides was determined with matrix-assisted laser desorption ionization time-of-flight mass spectrometry (MALDI-TOFMS) (Microflex, Bruker, Billerica, MA,

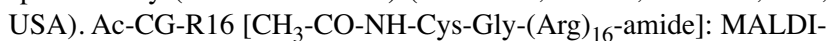
TOFMS: 2717.8 [calculated for $(\mathrm{M}+\mathrm{H})^{+}:$2717.7]. Retention time in HPLC, $11.6 \mathrm{~min}$ [column: Cosmosil 5C18-AR-II $(4.6 \times 150 \mathrm{~mm})$; gradient: $5-50 \% \mathrm{~B}$ in $\mathrm{A}\left(\mathrm{A}=\mathrm{H}_{2} \mathrm{O}\right.$ containing $0.1 \% \quad \mathrm{CF}_{3} \mathrm{COOH}$, $\mathrm{B}=\mathrm{CH}_{3} \mathrm{CN}$ containing $0.1 \% \mathrm{CF}_{3} \mathrm{COOH}$ ) over $30 \mathrm{~min}$ flow: $1 \mathrm{ml} / \mathrm{min}$; detection: $220 \mathrm{~nm}$ ]; and yield from the starting resin, $9.3 \%$.

Conjugation of $N$-E-maleimidocaproyl-oxysulfosuccinimide ester (EMCS) linker via the side chain of cysteine of the peptide sequence. The EMCS linker-conjugated peptide was prepared by mixing the purified peptides and EMCS (1.1 equivalent) (Thermo Fisher Scirntific Inc., Rockford, II, USA) in DMF for $2 \mathrm{~h}$ at $25^{\circ} \mathrm{C}$ followed by HPLC purification. R16-EMCS $\left[\mathrm{CH}_{3}-\mathrm{CO}-\mathrm{NH}-\right.$ Cys(EMCS)-Gly-(Arg) 16-amide]: MALDI-TOFMS: 3105.9 [calculated for $(\mathrm{M}+\mathrm{H})^{+}: 3105.1$ ]. Retention time in HPLC, $9.5 \mathrm{~min}$ [column: Cosmosil 5C18-AR-II $(4.6 \times 150 \mathrm{~mm})$; gradient: $5-95 \% \mathrm{~B}$ in $\mathrm{A}\left(\mathrm{A}=\mathrm{H}_{2} \mathrm{O}\right.$ containing $0.1 \% \mathrm{CF}_{3} \mathrm{COOH}, \mathrm{B}=\mathrm{CH}_{3} \mathrm{CN}$ containing $0.1 \% \mathrm{CF}_{3} \mathrm{COOH}$ ) over $30 \mathrm{~min}$ flow: $1 \mathrm{ml} / \mathrm{min}$; detection: $220 \mathrm{~nm}$ ]; yield from the starting resin, $4.9 \%$.

Cell culture. HeLa (human cervical cancer-derived) cells, Chinese hamster ovary (CHO)-K1 cells, and CHO-A745 cells (xylosyltransferase deficient cells), were purchased from the Riken BRC cell Bank (Ibaraki, Japan) (HeLa cells) and American Type Culture Collection (Manassas, VA, USA) (CHO-K1 cells and CHOA745 cells), respectively. Each cell line was grown on 100-mm dishes and incubated at $37^{\circ} \mathrm{C}$ under $5 \% \mathrm{CO}_{2}$.

Stably expressing green fluorescent protein (GFP)-fused CD63 in HeLa cells. CD63, also known as an EVs (exosomes) marker protein, is a tetraspanin protein located in exosomal membranes. We prepared HeLa cells stably expressing GFP-fused CD63 to obtain CD63-GFP-containing EVs (CD63-GFP-EVs) as previously reported (11). HeLa cells $\left(1 \times 10^{5}\right.$ cells $)$ were plated on a 24 -well microplate (Iwaki, Tokyo, Japan), incubated for 1 day, and then transfected with CD63-GFP-plasmid (pCT-CD63-GFP, pCMV, Cyto-Tracer, System Biosciences, Mountain View, CA, USA) (800 ng) complexed with Lipofectamine LTX reagent $(2 \mu \mathrm{l})$ and PLUS reagent $(1 \mu \mathrm{l})$ (Invitrogen, Life Technologies Corporation, Eugene, OR, USA) in $\alpha$-MEM containing $10 \%$ FBS $(200 \mu \mathrm{l})$. The cells were also treated with puromycin $(3 \mu \mathrm{g} / \mathrm{ml})$ (LKT Laboratories, St. Paul, MN, USA) for antibiotic selection of HeLa cells stably expressing CD63-GFP (CD63-GFP-HeLa).

Isolation of EVs. CD63-GFP-HeLa cells or HeLa cells $\left(2 \times 10^{6}\right.$ cells) were seeded on $100-\mathrm{mm}$ dishes in $\alpha$-MEM containing $10 \% \mathrm{EV}$-free FBS (EXO-FBS, ATLAS biological, Fort Collins, CO, USA) for 2 days. The EVs were isolated from the culture medium by using ultracentrifugation (18). To isolate the EVs, the cell culture medium was centrifuged $(300 \times g)$ for $10 \mathrm{~min}$ at $4^{\circ} \mathrm{C}$. The supernatant was centrifuged $\left(2,000 \times g\right.$ for $10 \mathrm{~min}$ at $4^{\circ} \mathrm{C}$ followed by $10,000 \times g$ for $30 \mathrm{~min}$ at $4^{\circ} \mathrm{C}$ ) to remove the cell debris. After centrifugation, the supernatant was centrifuged $(100,000 \times g)$ for $3 \mathrm{~h}$ at $4^{\circ} \mathrm{C}(\mathrm{Himac}$ CP85 $\beta$, Hitachi, Tokyo, Japan) in duplicate and the pellet was collected in PBS. The concentrations of the isolated EVs were described in terms of their protein concentrations, which were determined using a Pierce BCA protein assay kit (Thermo Fisher Scientific Inc., Rockford, IL., USA).

Western blotting analysis. To detect CD63, isolated EVs were treated with lysis buffer ( $50 \mathrm{mM}$ Tris- $\mathrm{HCl}(\mathrm{pH}=7.5), 150 \mathrm{mM} \mathrm{NaCl}$, $0.1 \%$ SDS, $1 \%$ Triton $\mathrm{X}-100$, and $1 \%$ sodium deoxycholate). The boiled samples were transferred onto polyvinylidene fluoride (PVDF) membranes (GE Healthcare, Pittsburgh, PA, USA) after separation by $10 \%$ SDS-PAGE. The PVDF membranes were incubated with the anti-CD63 primary antibody (TS63, Abcam, Cambridge, UK). A secondary antibody labelled with horseradish peroxidase (HRP) [anti-mouse IgG HRP (NA931V (GE Healthcare)] was then used, and immunoreactive species were detected using the Enhanced Chemiluminescence (ECL) Plus Western Blotting Detection System (GE Healthcare) with the Amersham Imager 600 (GE Healthcare). 
Preparation of R16-modified EVs and lyophilization. The R16EMCS peptide (final $1.8 \mathrm{mM}$ ) diluted in $\mathrm{H}_{2} \mathrm{O}$ was added to a solution of EVs $(36 \mu \mathrm{g})$ in PBS (total $57 \mu \mathrm{l})$ and incubated for 30 $\min$ at $25^{\circ} \mathrm{C}(10)$. After mixing, the R16 peptide-modified EVs were lyophilized using a freeze dryer (FDU-1200 EYELA, Tokyo Rikakikai Co, Ltd, Tokyo, Japan).

Zeta-potential and particle size. The zeta-potential and the particle size of EVs in PBS were analyzed using zeta-potential and particle size analyzer EISZ-DN2 (Otsuka Electronics, Osaka, Japan) according to the manufacturer's instructions.

Encapsulation of SAP into EVs. To encapsulate SAP (SigmaAldrich, St. Louis, MO, USA) into EVs by electroporation, the EVs $(25 \mu \mathrm{g})$ were mixed with SAP $(50 \mu \mathrm{g})$ in PBS $(100 \mu \mathrm{l})$. After electroporation [poring pulse: twice pulse $100 \mathrm{~V}, 5 \mathrm{msec}$, transfer pulse: five pulse $(20 \mathrm{~V}, 50 \mathrm{msec})]$ in a $1-\mathrm{cm}$ electroporation cuvette at $25^{\circ} \mathrm{C}$ using a super electroporator NEPA21 Type II (NEPA Genes, Tokyo, Japan), removal of the unencapsulated SAP was accomplished by washing and filtration using Amicon Ultra centrifugal filters (100K device, Merck Millipore, Billerica, MA, USA) as previously reported (8-10).

Electron microscopy. The EVs suspended in PBS $(20 \mu \mathrm{g} / \mathrm{ml})$ were dropped onto a carbon-coated copper grid (250-mesh) and then the excess was removed with a filter paper. Subsequently, $2 \%$ sodium phosphotungstate aqueous solution $(10 \mu \mathrm{l})$ was dropped onto the grid and dried in a desiccator overnight prior to imaging under a transmission electron microscope (TEM) (JEM-2000FEX II, JEOL, Tokyo, Japan) operated at $200 \mathrm{kV}$.

Flow cytometer. The CHO-K1 and CHO-A745 cells $\left(1.4 \times 10^{5}\right.$ cells $)$ were seeded on a 24-well microplate (Iwaki) and incubated in the Ham's F- 12 medium containing $10 \%$ FBS for $24 \mathrm{~h}$ at $37^{\circ} \mathrm{C}$ under $5 \%$ $\mathrm{CO}_{2}$. After complete adhesion, the cells were washed with cell culture medium containing 10\% FBS and treated with each EV sample $(600 \mu \mathrm{l} /$ well $)$ before washing with $0.5 \mathrm{mg} / \mathrm{ml}$ heparin dissolved in PBS (triple washing, $200 \mu \mathrm{l}$ ). The cells were then treated with $0.1 \mathrm{~g} / \mathrm{l}$-Trypsin/0.51 mmol/1-EDTA (Nacalai Tesque, Kyoto, Japan) at $37^{\circ} \mathrm{C}$ for $10 \mathrm{~min}$ prior to the addition of PBS $(200 \mu \mathrm{l})$ and then centrifuged at $800 \times \mathrm{g}$ for $5 \mathrm{~min}$ at $4^{\circ} \mathrm{C}$. After removal of the supernatant, the cells were washed with PBS $(400 \mu \mathrm{l})$ and centrifuged at $800 \times g$ for $5 \mathrm{~min}$ at $4^{\circ} \mathrm{C}$. This washing cycle was repeated, and the cells were suspended in PBS $(400 \mu \mathrm{l})$ and subjected to fluorescence analysis with a Guava ${ }^{\circledR}$ easyCyte (Merck Millipore) flow cytometer using 488-nm laser excitation and a 525-nm emission filter. For the detection of cellular fluorescence intensity, 10,000 cells/sample live cells were quantified based on forward-scattering and side-scattering analyses.

Evaluation of the biological activity of SAP (WST-1 assay). Analysis of cell viability was conducted for evaluating the biological activity of SAP using the WST-1 (4-[3-(4-iodophenyl)-2-(4-nitrophenyl)-2H-5tetrazolio]-1,3-benzene disulfonate) assay as previously described (810). CHO-K1 cells $\left(1 \times 10^{4}\right.$ cells, $\left.100 \mu \mathrm{l}\right)$ were incubated into 96 -well microplates in Ham's F-12 medium containing 10\% FBS for $24 \mathrm{~h}$ at $37^{\circ} \mathrm{C}$ under $5 \% \mathrm{CO}_{2}$. The cells were then treated with each EV sample $(50 \mu \mathrm{l})$ for $48 \mathrm{~h}$ at $37^{\circ} \mathrm{C}$ under $5 \% \mathrm{CO}_{2}$. After sample treatment, WST1 reagents $(10 \mu \mathrm{l})$ were added to each well and the samples were incubated for $40 \mathrm{~min}$ at $37^{\circ} \mathrm{C}$. The absorbances at $450 \mathrm{~nm}$ (A450) and
$620 \mathrm{~nm}$ (A620) were determined. The value obtained by subtracting A620 from A450 corresponded to the viable cell number.

Statistical analyses. All statistical analyses were conducted by using the GraphPad Prism software (ver. 5.00; GraphPad, San Diego, CA, USA). The data are presented as the mean \pm standard deviation (SD). For comparisons of the two groups, unpaired Student's $t$-test (twotailed) was used after verification of equal variances by an F-test. For comparisons among more than three groups, a two-way analysis of variance (ANOVA) followed by Bonferroni's post-hoc test was used. Differences were considered significant when the calculated $p$-value was $<0.05$.

\section{Results}

Characteristic confirmation of the isolated EVs after lyophilization. EVs were isolated by ultracentrifugation (18) as described above and their identity was confirmed by examining the expression of CD63, a tetraspanin membrane protein, which is an EV (exosome) marker protein (19). Figure 1A shows the results of the western blot analysis of CD63 expression in the isolated EVs. EVs isolated in PBS were lyophilized without any additives. The lyophilized EVs were reconstituted using $\mathrm{H}_{2} \mathrm{O}$ at a volume similar to the original PBS. After lyophilization and reconstitution in $\mathrm{H}_{2} \mathrm{O}$, western blot analysis of the EV sample showed that the expression of CD63 was similar to that before lyophilization (Figure 1A). The particle size of EVs was not affected by lyophilization and reconstitution in $\mathrm{H}_{2} \mathrm{O}$ (Figure 1B). In addition, the zeta-potential of the EVs showed almost the same ca. - $10 \mathrm{mV}$ before and after lyophilization (Figure 1C). The results suggested that our lyophilization and reconstitution methods did not affect the structure and characteristics of the isolated EVs.

Preparation of the RI6 peptide-modified EVs and characteristic confirmation and cellular uptake of the EVs after lyophilization. In our previous report, we have shown that macropinocytosis (ruffling of cell plasma membranes) by actin reorganization and engulfment of large volume of fluids ( $>1 \mu \mathrm{m}$ diameter) outside the cells (20-22) is an important cellular uptake route of EVs (23). Further modification of the arginine-rich CPPs, which can induce macropinocytosis $(24,25)$ of the EV membranes, significantly enhances their internalization by the target cells $(9,10)$. Hexadeca oligoarginine $\left[(\mathrm{Arg})_{16}, \mathrm{R} 16\right]$ is one of the arginine-rich CPPs, and we have already reported that incorporation of the R16 peptides on EV membranes significantly increased the cellular EVs uptake (10). The sulfo EMCS linker, which has both succinimide and maleimide moieties, was used to covalently conjugate the sulfhydryl of the Cys residue of the peptide and the amino group (e.g. Lys residue) of the $\mathrm{EV}$ membrane proteins (Figure 2A). As previously reported, $1.0 \mu \mathrm{M}$ of R16 peptides 


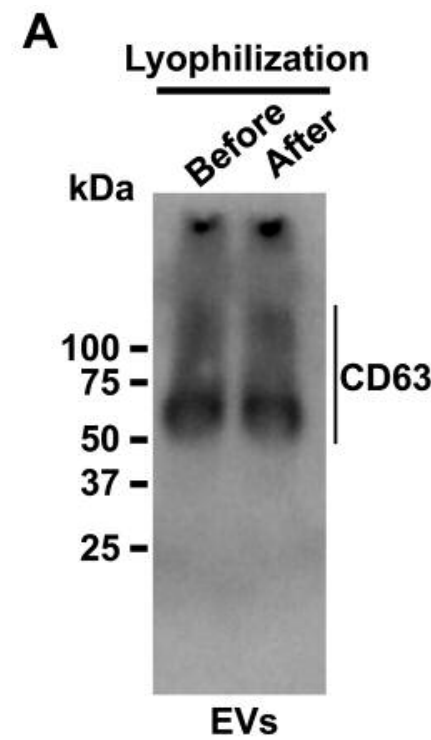

B

\begin{tabular}{|c|c|}
\hline EVs & Particle size $(\mathrm{nm})$ \\
\hline Before lyophilization & $76.7 \pm 22.5$ \\
\hline After lyophilization & $85.9 \pm 38.7$ \\
\hline \multicolumn{2}{|l|}{ C } \\
\hline EVs & $\zeta$-potential (mv) \\
\hline Before lyophilization & -9.66 \\
\hline After lyophilization & -10.6 \\
\hline
\end{tabular}

\section{EVs}

Figure 1. Confirmation of the characteristic of the isolated EVs after lyophilization. (A) Western blot analysis for CD63, tetraspanin and EV (exosome) marker, of the isolated EVs before or after lyophilization. (B) Particle size $(C)$ zeta-potential analyses of the isolated EVs before or after lyophilization.

was attached to the EVs $(20 \mu \mathrm{g} / \mathrm{ml})$ by the addition of R16EMCS $(10 \mu \mathrm{M})$ (Figure 2A) (10). The R16 peptide-modified EVs were also lyophilized following similar methods as depicted in Figure 1. The particle structure of the R16 peptide-modified EVs was assessed under a TEM and the vesicular structure of the EVs after peptide modification were confirmed (Figure 2B). The zeta-potential of the R16EVs was almost the same (ca. $13 \mathrm{mV}$ ) before and after lyophilization (Figure 2C). The results suggest that our lyophilization and reconstitution methods did not affect the structure and characteristics of the R16-EVs.

We have already prepared green fluorescent protein (GFP)fused CD63 (CD63-GFP) stably expressing HeLa cells, and identified that CD63-GFP-expressing EVs were secreted from these cells (11). We next investigated the cellular uptake efficacy of the CD63-GFP-EVs with or without modification with R16 peptides. CHO-K1 cells were treated with each EV sample $(20 \mu \mathrm{g} / \mathrm{ml})$ for $24 \mathrm{~h}$ at $37^{\circ} \mathrm{C}$ before analysis by flow cytometry as described above. Modification of EVs with R16 peptides (R16-CD63-GFP-EVs) significantly enhanced the cellular uptake in comparison to that of non-modified EVs (Figure 3A). The lyophilized R16-CD63-GFP-EVs were also efficiently taken up by the cells at a level similar to that of the non-lyophilized EVs (Figure 3A). In addition, we examined the cellular uptake efficacy of the R16 peptide-modified EVs into the CHO-A745 cells, which are deficient in all sugar chains of proteoglycans (Figure 3B and C), because the arginine-rich CPPs highly depend on the sugar chains of proteoglycans including heparan sulfate and chondroitin sulfate for induction of macropinocytosis and effective cellular uptake (25). We confirmed that the deficiency of sugar chains on the cellular membrane reduced the cellular uptake efficacy of R16-CD63-GFP-EVs (Figure 3B). Lyophilization of R16CD63-GFP-EVs resulted also in the reduction of their cellular uptake efficacy in the CHO-A745 cells (Figure 3C) suggesting that the R16 peptides, which were attached on the EV membrane, are considered to depend on the sugar chains of proteoglycans even after lyophilization.

Effects of lyophilization on the biological activity of SAPencapsulated R16-EVs. To assess the intracellular delivery of therapeutic proteins encapsulated in EVs, we prepared SAPencapsulated EVs (SAP-EVs) by electroporation. SAP is a ribosome-inactivating protein, which shows biological activity in the cytosol after cell membrane penetration, leading to cell death (26). Therefore, SAP has been applied as an anti-cancer drug, for example in combination with an antibody (26). We have already developed methods of SAP encapsulation into EVs (8-10), and the encapsulation efficacy has been calculated to be $65 \mathrm{ng} / \mathrm{ml}$ of SAP in $20 \mu \mathrm{g} / \mathrm{ml}$ of EVs as assessed using fluorescently-labeled SAP. SAPencapsulated EVs were modified with R16-EMCS (R16SAP-EVs) as depicted in Figure 2A. Before assessments of the biological activity of R16-SAP-EVs, we tested the effects of lyophilization of SAP without encapsulation in EVs on the biological activity of cell death. Figure 4A shows the viability of CHO-K1 cells which were treated with SAP for $48 \mathrm{~h}$ at $37^{\circ} \mathrm{C}$. Induction of cell death was dependent on SAP 

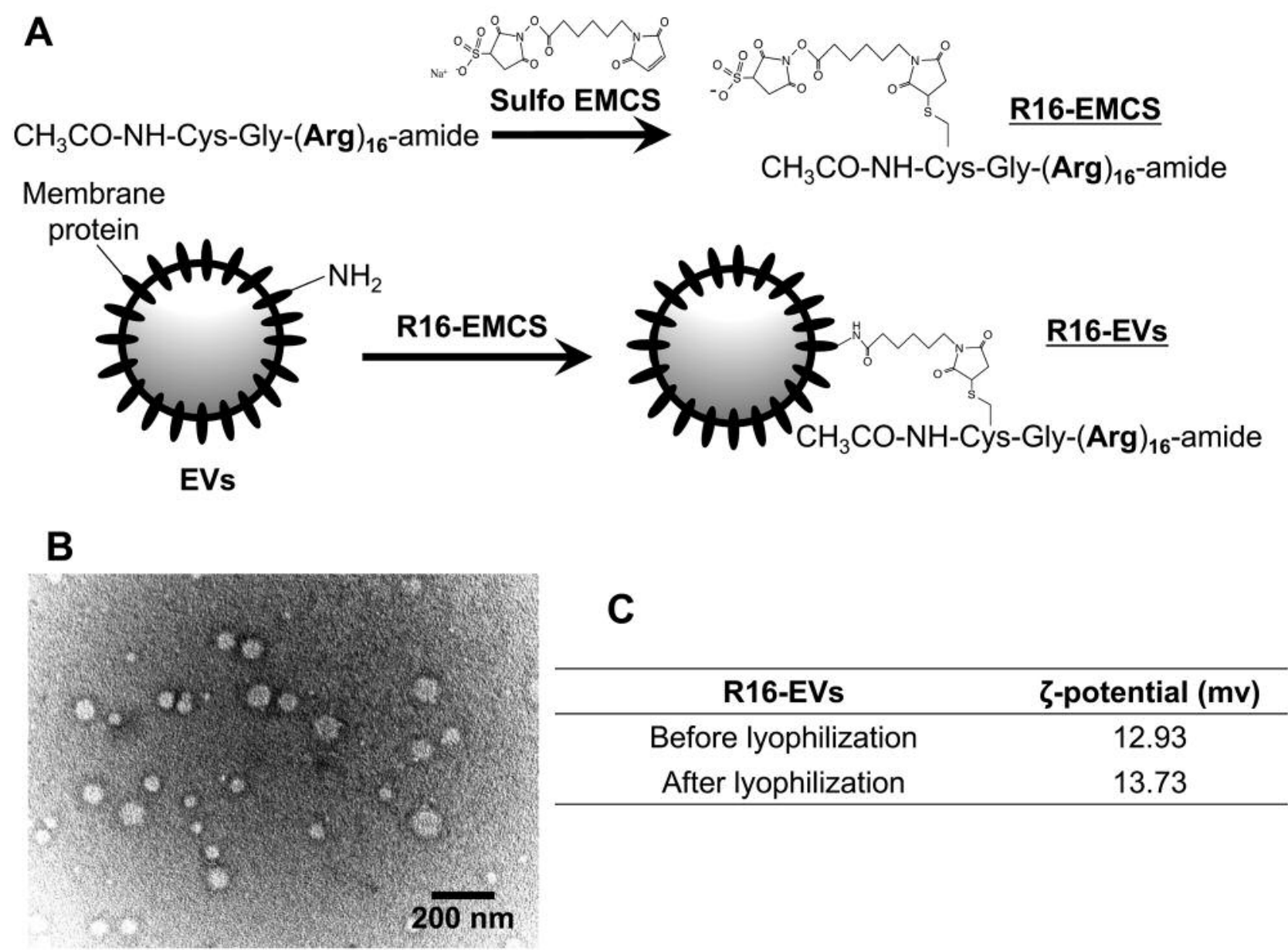

Figure 2. Preparation of R16 peptide-modified EVs and confirmation of the characteristics of EVs after lyophilization. (A) Scheme of R16 peptide modification of the EV membranes. A linker of sulfo EMCS was conjugated to the Cys side chain of the R16 peptide sequence (R16-EMCS). The EVs were then reacted with R16-EMCS to conjugate via the amino group of the EV membrane proteins (R16-EVs). (B) Transmission electron microscopic observation of the isolated R16-EVs after lyophilization and recovery in $\mathrm{H}_{2} \mathrm{O}$. Scale bar: $200 \mathrm{~nm}$. (C) Zeta-potential analyses of R16EVs before or after lyophilization.

concentration as assessed by WST-1 assay, and lyophilization of SAP did not affect the biological activity (Figure 4A).

The CHO-K1 cells were treated with SAP-EVs $(20 \mu \mathrm{g} / \mathrm{mL})$ for $48 \mathrm{~h}$ at $37^{\circ} \mathrm{C}$, and cell viability was assessed by the WST1 assay. Modification of EV membranes with R16 peptides significantly enhanced induction of cell death (Figure 4B) as previously reported (10). However, lyophilization of R16SAP-EVs completely prevented the induction of cell death (Figure 4B). Similar results were obtained by microscopic observation (Figure 4C). As mentioned above, lyophilization of R16 peptide-modified EVs and SAP did not affect their cellular uptake and biological activity (Figures 3A and 4A). However, lyophilization of R16-SAP-EVs highly reduced the biological activity of SAP (Figure 4B and C), suggesting that lyophilization of the EVs might affect SAP structures and/or reduce the cytosolic release efficacy of the EV content after cellular uptake.

\section{Discussion}

Lyophilization methods are useful for maintaining the biological activity of proteins following long-term storage even at room temperature. Therefore, these methods have been widely used, especially in various therapeutic reagents. In this study, we evaluated the effects of lyophilization of EVs on their cellular uptake and biological activity. Lyophilization of EVs did not affect the particle size and zetapotential (Figure 1). In addition, lyophilization of the R16peptide-modified EVs maintained the particle structures without any aggregations as observed under a TEM (Figure 

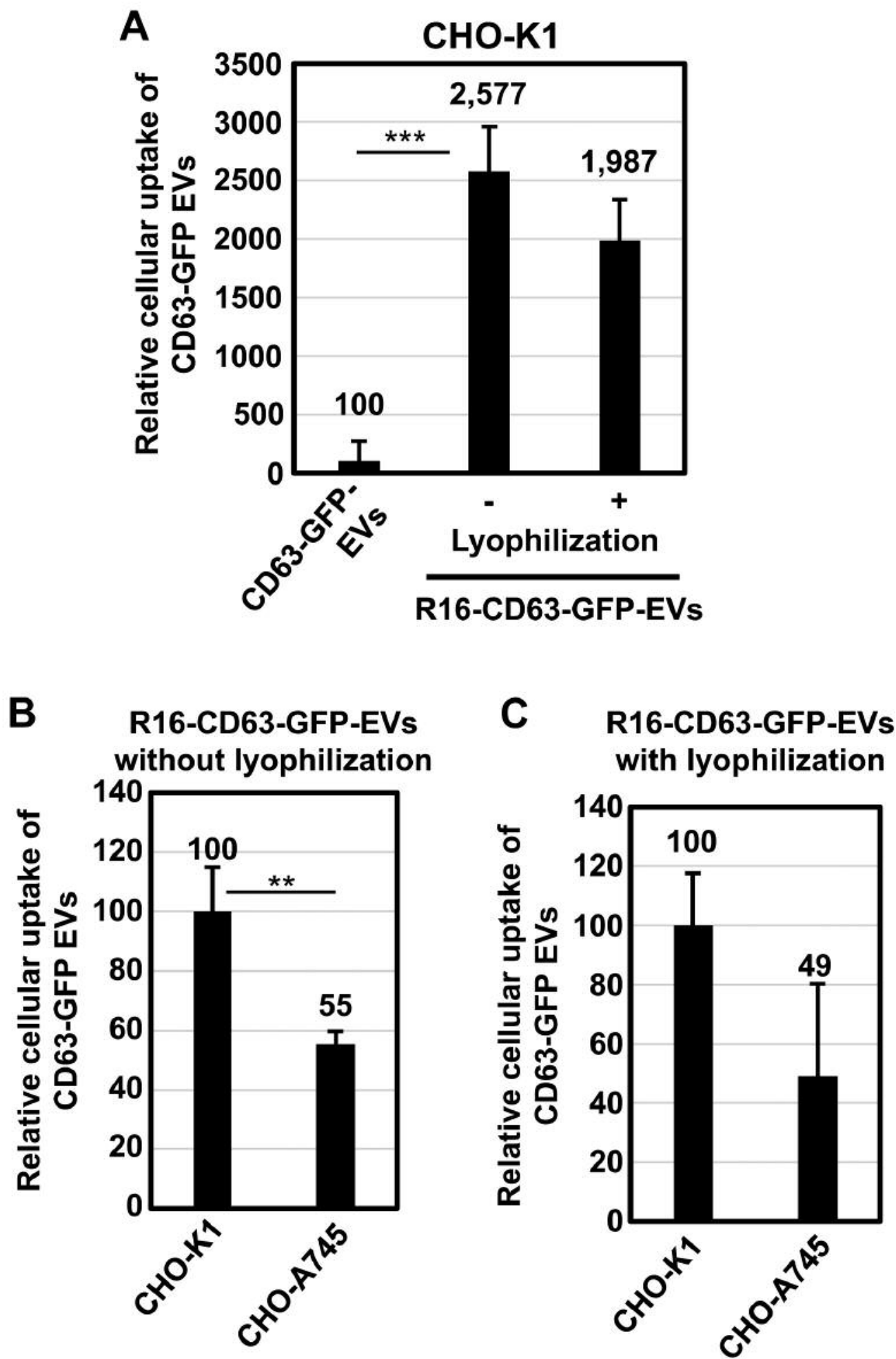

Figure 3. Cellular uptake of R16 peptide-modified EVs after lyophilization. (A) Relative cellular uptake of CD63-GFP-EVs or R16-CD63-GFP-EVs with or without lyophilization into the CHO-K1 cells (10\% FBS contained F-12 medium at $37^{\circ} \mathrm{C}$ for 24 h) analyzed using a flow cytometer. The data are expressed as the mean $\pm S D$ of three experiments. $* * * p<0.001 .(B, C)$ Comparison of the cellular uptake of R16-CD63-GFP-EVs with $(C)$ or without $(B)$ lyophilization into $\mathrm{CHO}-\mathrm{K} 1$ or $\mathrm{CHO}-\mathrm{A} 745$ cells (all glycosaminoglycan deficient) $\left(37^{\circ} \mathrm{C}, 24 \mathrm{~h}\right)$ analyzed using a flow cytometer. The data are expressed as the mean $\pm S D$ of three experiments. $* * p<0.01$. 
A

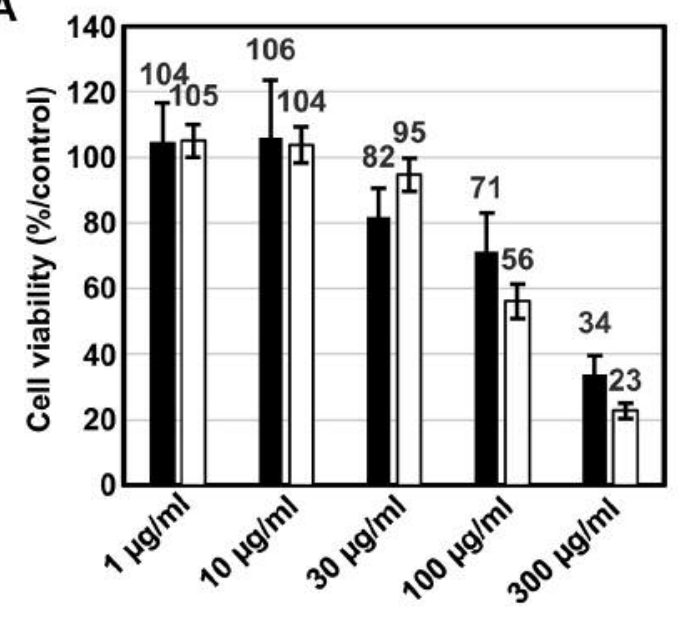

B

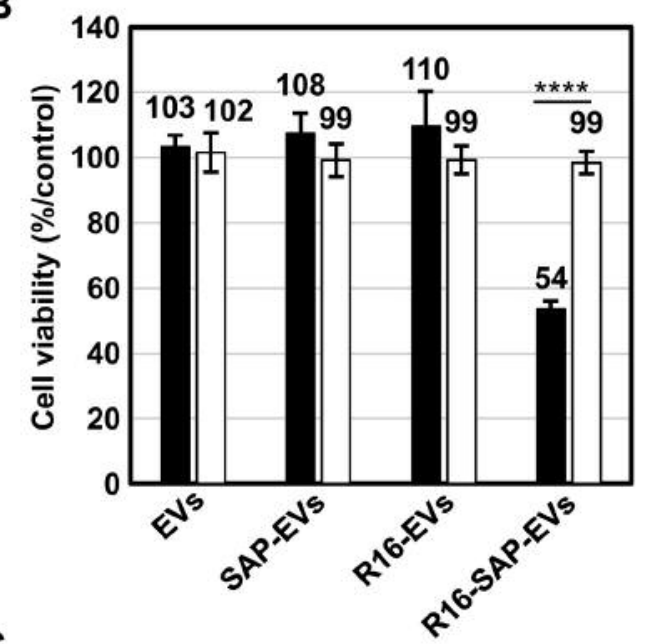

C

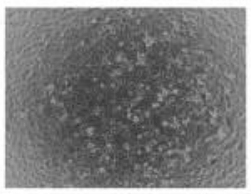

No treatment

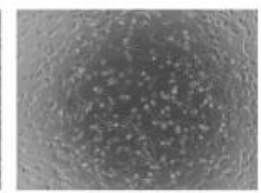

$-$ Lyophilization
R16-SAP-EVs

Figure 4. Effects of lyophilization on the biological activity of SAPencapsulated R16-EVs. (A) Viability of the CHO-Kl cells treated with SAP $\left(10 \%\right.$ FBS contained F-12 medium at $37^{\circ} \mathrm{C}$ for $\left.48 \mathrm{~h}\right)$ before or after lyophilization and analyzed by WST-1 assay. The data are expressed as the mean $\pm S D$ of three experiments. (B) Viability of the CHO-K1 cells treated with EVs (without modification of R16 peptide and SAPencapsulation), SAP-EVs (SAP-encapsulation in EVs without R16 modification), R16-EVs (R16 modification on EV membranes without SAP-encapsulation in EVs), and R16-SAP-EVs (with modification of R16 peptide and SAP-encapsulation) (10\% FBS contained F-12 medium at $37^{\circ} \mathrm{C}$ for $48 \mathrm{~h}$ ) before or after lyophilization and analyzed by WST-1 assay. The data are expressed as the mean $\pm S D$ of three experiments. ****p<0.0001. (C) Microscopic observation of the CHO-K1 cells after treatment of R16-SAP-EVs with or without lyophilization under the same experimental condition as in $(B)$.
2B). Trehalose has been used during lyophilization for the prevention of EV aggregation and retention of their biological activity $(13,14)$, however, we did not use trehalose in our experiments, and aggregation of the EVs was not observed (Figures 1 and 2B). The species of cell types, which secret EVs possibly affect the degree of EV aggregation after lyophilization because of their differential molecular content. Further, the isolation methods of EVs are also considered to affect the aggregation tendency by lyophilization.

We examined the cellular uptake efficacy of the EVs. Modification of EV membranes with R16 peptides significantly enhanced the internalization of EVs by CHOK1 cells (Figure 3A). The cellular uptake efficacy was not significantly affected by the lyophilization of the EVs (Figure 3A). Besides, the R16-peptide-modified EVs were highly taken up by the CHO-K1 as compared to that of the CHO-A745 cells which were glycosaminoglycans deficient, even after lyophilization (Figure $3 \mathrm{~B}$ and C). These results suggested that dependency of the modified R16 peptides on sugar chains for cellular uptake after lyophilization of EVs were retained.

Next, the cytosolic release of the EV content and its biological activity after cellular uptake was examined by the encapsulation of SAP. The SAP is a ribosomeinactivating protein, and the cytosolic release of SAP is needed to induce its biological activity (26). The lyophilized SAP without encapsulation into EVs showed cytotoxic activity almost similar level to that of the nonlyophilized (Figure 4A), suggesting that lyophilization did not affect the biological activity of SAP. However, in the case of SAP-encapsulated R16-modified EVs, the cytotoxic activity was completely prevented by lyophilization (Figure $4 \mathrm{~B}$ and $\mathrm{C})$. The various reasons behind this effect are considered to be as follows: (i) only aggregation of SAP in the EVs after lyophilization, (ii) secondary structural changes of the SAP, (iii) reduction of the cytosolic release efficacy of the encapsulated SAP in EVs by lyophilization, and (iv) enhanced protection against cell death by lyophilized EVs. However, the functionality of molecules used to modify EV membranes, might be retained even after lyophilization, although further studies are needed to elucidate the actual mechanisms.

To conclude, in this study, we demonstrated that lyophilization of EVs did not affect the functionality of the peptides used to modify the EV membranes; however, the biological activity of proteins encapsulated in the EVs was highly affected after cellular uptake. These findings are very important for the development of EV-based therapeutic and/or diagnostic methodology.

\section{Conflicts of Interest}

The Authors declare no conflicts of interest regarding this study. 


\section{Authors' Contributions}

I.N. designed the study. K.N., M.H., T.H., E.Y., T.T.-N., and I.N. performed the experiments. Statistical analysis was conducted by T.T.-N. The manuscript was written by K.N. and I.N. All Authors discussed and analyzed the obtained results.

\section{Acknowledgements}

The study was supported in part by JSPS KAKENHI (JP16H02612 and JP19H05553 for I.N.) and JST CREST (JPMJCRI7H3 for I.N.). This study was also supported by the Leading University as a Base for Human Resource Development in Nanoscience and Nanotechnology, Osaka Prefecture University. The manuscript preparation was assisted by Kayo Hirano (Osaka Prefecture University).

\section{References}

1 Raposo G and Stoorvogel W: Extracellular vesicles: exosomes, microvesicles, and friends. J Cell Biol 200: 373-383, 2013. PMID: 23420871. DOI: 10.1083/jcb.201211138

2 Yáñez-Mó M, Siljander PR, Andreu Z, Zavec AB, Borràs FE, Buzas EI, Buzas K, Casal E, Cappello F, Carvalho J, Colás E, Cordeiro-da Silva A, Fais S, Falcon-Perez JM, Ghobrial IM, Giebel B, Gimona M, Graner M, Gursel I, Gursel M, Heegaard NH, Hendrix A, Kierulf P, Kokubun K, Kosanovic M, KraljIglic V, Krämer-Albers EM, Laitinen S, Lässer C, Lener T, Ligeti E, Linē A, Lipps G, Llorente A, Lötvall J, Manček-Keber M, Marcilla A, Mittelbrunn M, Nazarenko I, Nolte-'t Hoen EN, Nyman TA, O'Driscoll L, Olivan M, Oliveira C, Pállinger É, Del Portillo HA, Reventós J, Rigau M, Rohde E, Sammar M, Sánchez-Madrid F, Santarém N, Schallmoser K, Ostenfeld MS, Stoorvogel W, Stukelj R, Van der Grein SG, Vasconcelos MH, Wauben MH, De Wever O: Biological properties of extracellular vesicles and their physiological functions. J Extracell Vesicles 4: 27066, 2015. PMID: 25979354. DOI: 10.3402/jev.v4.27066

3 Yamamoto $\mathrm{T}$, Kosaka $\mathrm{N}$ and Ochiya $\mathrm{T}$ : Latest advances in extracellular vesicles: from bench to bedside. Sci Technol Adv Mater 20: 746-757, 2019. PMID: 31447954. DOI: 10.1080/14686996.2019.1629835

4 Jiang L, Gu Y, Du Y and Liu J: Exosomes: diagnostic biomarkers and therapeutic delivery vehicles for cancer. Mol Pharm 16: 3333-3349, 2019. PMID: 31241965. DOI: 10.1021/ acs.molpharmaceut.9b00409

5 Alvarez-Erviti L, Seow Y, Yin H, Betts C, Lakhal S and Wood MJ: Delivery of siRNA to the mouse brain by systemic injection of targeted exosomes. Nat Biotechnol 29: 341-345, 2011. PMID: 21423189. DOI: $10.1038 /$ nbt. 1807

6 Kooijmans SA, Aleza CG, Roffler SR, van Solinge WW, Vader $\mathrm{P}$ and Schiffelers RM: Display of GPI-anchored anti-EGFR nanobodies on extracellular vesicles promotes tumour cell targeting. J Extracell Vesicles 5: 31053, 2016. PMID: 26979463. DOI: $10.3402 /$ jev.v5.31053

7 Limoni SK, Moghadam MF, Moazzeni SM, Gomari H and Salimi F: Engineered exosomes for targeted transfer of sirna to HER2 positive breast cancer cells. Appl Biochem Biotechnol 187: 352364, 2019. PMID: 29951961. DOI: 10.1007/s12010-018-2813-4
8 Nakase I, Ueno N, Katayama M, Noguchi K, Takatani-Nakase T, Kobayashi NB, Yoshida T, Fujii I and Futaki S: Receptor clustering and activation by multivalent interaction through recognition peptides presented on exosomes. Chem Commun (Camb) 53: 317-320, 2017. PMID: 27853769. DOI: $10.1039 / \mathrm{c} 6 \mathrm{cc} 06719 \mathrm{k}$

9 Nakase I, Noguchi K, Fujii I and Futaki S: Vectorization of biomacromolecules into cells using extracellular vesicles with enhanced internalization induced by macropinocytosis. Sci Rep 6: 34937, 2016. PMID: 27748399. DOI: 10.1038/srep34937

10 Nakase I, Noguchi K, Aoki A, Takatani-Nakase T, Fujii I and Futaki S: Arginine-rich cell-penetrating peptide-modified extracellular vesicles for active macropinocytosis induction and efficient intracellular delivery. Sci Rep 7: 1991, 2017. PMID: 28512335. DOI: 10.1038/s41598-017-02014-6

11 Nakase I and Futaki S: Combined treatment with a pH-sensitive fusogenic peptide and cationic lipids achieves enhanced cytosolic delivery of exosomes. Sci Rep 5: 10112, 2015. PMID: 26011176. DOI: 10.1038/srep10112

12 Akers JC, Ramakrishnan V, Yang I, Hua W, Mao Y, Carter BS and Chen CC: Optimizing preservation of extracellular vesicular miRNAs derived from clinical cerebrospinal fluid. Cancer Biomark 17: 125-132, 2016. PMID: 27062568. DOI: 10.3233/ CBM-160609

13 Charoenviriyakul C, Takahashi Y, Nishikawa M and Takakura Y: Preservation of exosomes at room temperature using lyophilization. Int J Pharm 553: 1-7, 2018. PMID: 30316791. DOI: $10.1016 /$ j.ijpharm.2018.10.032

14 Frank J, Richter M, de Rossi C, Lehr CM, Fuhrmann K and Fuhrmann G: Extracellular vesicles protect glucuronidase model enzymes during freeze-drying. Sci Rep 8: 12377, 2018. PMID: 30120298. DOI: 10.1038/s41598-018-30786-y

15 Futaki S, Ohashi W, Suzuki T, Niwa M, Tanaka S, Ueda K, Harashima H and Sugiura Y: Stearylated arginine-rich peptides: a new class of transfection systems. Bioconjug Chem 12: 10051011, 2001. PMID: 11716693. DOI: 10.1021/bc015508I

16 Nakase I, Tadokoro A, Kawabata N, Takeuchi T, Katoh H, Hiramoto K, Negishi M, Nomizu M, Sugiura Y and Futaki S: Interaction of arginine-rich peptides with membrane-associated proteoglycans is crucial for induction of actin organization and macropinocytosis. Biochemistry 46: 492-501, 2007. PMID: 17209559. DOI: $10.1021 /$ bi0612824

17 Nakase I, Okumura S, Tanaka G, Osaki K, Imanishi M and Futaki S: Signal transduction using an artificial receptor system that undergoes dimerization upon addition of a bivalent leucinezipper ligand. Angew Chem Int Ed Engl 51: 7464-7467, 2012. PMID: 22711581. DOI: 10.1002/anie.201201805

18 Théry C, Amigorena S, Raposo G and Clayton A: Isolation and characterization of exosomes from cell culture supernatants and biological fluids. Curr Protoc Cell Biol Chapter 3: Unit 3.22, 2006. PMID: 18228490. DOI: 10.1002/0471143030.cb0322s30

19 Schorey JS and Bhatnagar S: Exosome function: from tumor immunology to pathogen biology. Traffic 9: 871-881, 2008. PMID: 18331451. DOI: 10.1111/j.1600-0854.2008.00734.x

20 Swanson JA and Watts C: Macropinocytosis. Trends Cell Biol 5: 424-428, 1995. PMID: 14732047. DOI: 10.1016/s09628924(00)89101-1

21 Conner SD and Schmid SL: Regulated portals of entry into the cell. Nature 422: 37-44, 2003. PMID: 12621426. DOI: 10.1038/nature01451 
22 Swanson JA: Shaping cups into phagosomes and macropinosomes. Nat Rev Mol Cell Biol 9: 639-649, 2008. PMID: 18612320 . DOI: $10.1038 / \mathrm{nrm} 2447$

23 Nakase I, Kobayashi NB, Takatani-Nakase T and Yoshida T: Active macropinocytosis induction by stimulation of epidermal growth factor receptor and oncogenic Ras expression potentiates cellular uptake efficacy of exosomes. Sci Rep 5: 10300, 2015. PMID: 26036864. DOI: 10.1038/srep10300

24 Nakase I, Niwa M, Takeuchi T, Sonomura K, Kawabata N, Koike Y, Takehashi M, Tanaka S, Ueda K, Simpson JC, Jones AT, Sugiura Y and Futaki S: Cellular uptake of arginine-rich peptides: roles for macropinocytosis and actin rearrangement. Mol Ther 10: 1011-1022, 2004. PMID: 15564133. DOI: $10.1016 /$ j.ymthe. 2004.08 .010
25 Futaki S and Nakase I: Cell-surface interactions on arginine-rich cell-penetrating peptides allow for multiplex modes of internalization. Acc Chem Res 50: 2449-2456, 2017. PMID: 28910080. DOI: $10.1021 /$ acs.accounts.7b00221

26 Fabbrini MS, Katayama M, Nakase I and Vago R: Plant ribosome-inactivating proteins: progesses, challenges and biotechnological applications (and a few digressions). Toxins (Basel) 9: E314, 2017. PMID: 29023422. DOI: 10.3390/toxins 9100314

Received October 9, 2019

Revised November 1, 2019

Accepted November 4, 2019 